This is the peer reviewed version of the following article: "Gustini, L., Lavilla, C., Janssen, W., Martínez de Ilarduya, A., Muñoz-Guerra, S. and Koning, C. (2016). Green and selective polycondensation methods toward linear sorbitol-based polyesters: enzymatic versus organic and metal-based catalysis. ChemSusChem, (9), 16: 2250-2260." which has been published in final form at [doi: 10.1002/cssc.201600626]. This article may be used for noncommercial purposes in accordance with Wiley Terms and Conditions for SelfArchiving." 


\title{
Green and selective polycondensation methods toward linear sorbitol-based polyesters: enzymatic vs. organic and metal-based catalysis
}

\author{
Liliana Gustini ${ }^{[a, b]}$, Cristina Lavilla *[a], William W.T.J. Janssen ${ }^{[a]}$, Antxon Martínez de Ilarduya ${ }^{[c]}$, \\ Sebastián Muñoz-Guerra ${ }^{[c]}$, Cor E. Koning ${ }^{[a, d]}$
}

\begin{abstract}
Renewable polyesters derived from a sugar alcohol, i.e. sorbitol, were synthesized by solvent-free polycondensation. The aim was to prepare linear polyesters with pendant hydroxyl groups along the polymer backbone. The performance of the sustainable biocatalyst SPRIN liposorb CALB and the organo-base catalyst triazobiciclodecene were compared with two metal-based catalysts, viz. scandium trifluoromethanesulfonate and dibutyl tin oxide. For the four catalytic systems, the efficiency and selectivity for the implementation of sorbitol were studied, mainly via ${ }^{13} \mathrm{C}$ and ${ }^{31} \mathrm{P}$ NMR spectroscopies, while side reactions such as ether formation and dehydration of sorbitol were evaluated via MALDI-ToF-MS. Especially the biocatalyst SPRIN liposorb CALB succeeded in incorporating sorbitol in a selective way without side reactions, leading to close-to-linear polyesters. By using a renewable hydroxylreactive curing agent based on L-lysine, transparent and glossy poly(ester urethane) networks were successfully synthesized offering a tangible example of bio-based coatings.
\end{abstract}

\section{Introduction}

An ever-increasing growing range of chemicals can be produced from renewable resources such as starch, cellulose and vegetable oils. Some of these bio-based compounds are becoming a potential source for the synthesis of new sustainable polymeric materials. ${ }^{1}$ Sorbitol is one of the top 10 renewable building blocks, being mostly used in the food industry or as platform chemical for the production of isosorbide and glycols at low cost. $^{2}$ In fact, isosorbide has proved to be a very effective monomer to enhance the stiffness and accordingly the glass transition temperature of polymers. Recently more focus has been given to sorbitol itself as a readily available monomer for applications such as textiles, packaging and for the synthesis of commodity chemicals and renewable resins.,

\footnotetext{
[a] L. Gustini, Dr. C. Lavilla, W.W.T.J. Janssen, Prof. C.E. Koning Laboratory of Physical Chemistry Eindhoven University of Technology P.O. Box 513, 5600 MB Eindhoven, The Netherlands E-mail: C.LavillaAguilar@tue.nl

[b] L. Gustini Dutch Polymer Institute P.O. Box 902, 5600 AX Eindhoven, The Netherlands

[c] Dr. A. Martínez de llarduya, Prof. S. Muñoz-Guerra Departament d'Enginyeria Química, ETSEIB Universitat Politècnica de Catalunya Diagonal 647, 08028 Barcelona, Spain

[d] Prof. C.E. Koning DSM Coating Resins Ceintuurbaan 5, Zwolle, The Netherlands
}

Supporting information for this article is given via a link at the end of the document
For coating applications, polyesters with high hydroxyl functionality and molecular weights in the range of 3-6 $\mathrm{kg} / \mathrm{mol}$ are interesting candidates. Once these polyesters are prepared, they are usually cross-linked with hydroxyl-reactive curing reagents to form a poly(ester urethane) network. An increase in the functionalization of the aliphatic polyesters could result in the improvement of the properties of the final networks. Sorbitol, in principle, can be directly used in polyester synthesis, e.g. via polycondensation, but because of its multiple hydroxyl groups, the preparation of highly functional, linear polyesters is challenging. Polycondensation reactions using classic catalysts usually require relatively high temperatures, at which sorbitol may not be thermally stable and is transferred into isosorbide and/or sorbitan ${ }^{5}$ or result in cross-linked and intractable materials. In the case of low temperature polycondensation, acid or base-catalyzed conditions are necessary at which sorbitol also may dehydrate to sorbitan and, further, to isosorbide giving a broad distribution of different products. ${ }^{6,7}$ Only specific reaction conditions and a good control over selective ester bond formation, for example by limiting esterification reactions to the two primary hydroxyl groups and leaving the four secondary hydroxyls unaffected, will guarantee its integrity and the linearity of the obtained polyester, leaving pendant (secondary) functional hydroxyl groups available for further modifications. Thus, the development of powerful tools permitting the use of raw carbohydrates for the synthesis of sustainable polymers, especially by employing eco-friendly catalytic chemistry, is of extreme importance.

The aim of this work is to compare four different catalysts for the synthesis of close to linear, hydroxyl-functional sorbitol-based polyesters with molecular characteristics adequate for coating applications. 1,3-Propanediol and adipic acid will be used as comonomers for sorbitol. Nowadays both these comonomers can be obtained from renewable resources. ${ }^{8,9}$ The catalyst selection includes two metal-based catalysts: dibutyl tin oxide (DBTO) and scandium trifluoromethanesulfonate (also known as scandium triflate, $\left.\mathrm{Sc}(\mathrm{OTf})_{3}\right)$. DBTO is known to effectively catalyze polycondensation reactions at temperatures around 140-150 ${ }^{\circ} \mathrm{C} .{ }^{10,11}$ The Lewis acid $\mathrm{Sc}(\mathrm{OTf})_{3}$ has been used for several types of reactions including polycondensation/polyesterification at low temperature $\left(60^{\circ} \mathrm{C}\right)$, showing high selectivity for primary over secondary hydroxyl groups and low toxicity. ${ }^{12}$ Two metal-free catalytic systems, known to be active at mild reaction conditions, will also be compared for the synthesis of poly(1,3-propylene-co-sorbitol adipate)s: an immobilized form of Candida antarctica lipase B (CALB), known as SPRIN liposorb CALB, and the organo-base 1,5,7-triazabicyclo[4,4,0]dec-5-ene (TBD). In its natural environment, CALB is responsible for the cleavage of the ester bonds in fatty acid-based molecules like triglycerides. However, when in an organic environment, CALB shows to promote ester 
bond formation, displaying high selectivity for primary over secondary hydroxyl groups, and it is one of the most eco-friendly catalytic ways with potentiality for recycling. ${ }^{13}$ TBD is a strong guanidine base, originally developed as catalyst for the ringopening polymerization of lactones, ${ }^{14}$ and it has recently been used in polycondensation chemistry to synthesize polyurethanes ${ }^{15,16}$ and polyesters. ${ }^{17}$ As an organo-based catalyst, TBD can be considered a suitable metal-free catalyst alternative for the synthesis of polyesters which are used in compostable packaging or for biomedical applications. ${ }^{18}$

The reactions will be performed in an eco-friendly, solvent-free approach. Relevant factors in this comparison study will be the amount of sorbitol implemented into the final polyester, the amount of catalyst used, the reaction time necessary to reach the required number-average molecular weight for coating applications and the properties of the final polyester. Especially the selectivity for the primary over the secondary hydroxyl groups of sorbitol and the existence of side reactions are of crucial importance. The molecular characteristics of the biobased polyesters will be studied in detail by a number of experimental techniques including ${ }^{13} \mathrm{C} N \mathrm{NMR}$ and ${ }^{31} \mathrm{P} N M R$ spectroscopies, potentiometric titration and MALDI-ToF-MS. The hydroxyl-functional sorbitol-based polyesters will be cured with conventional, petroleum-based and with bio-based hydroxylreactive curing agents, and the properties of the resulting coatings will be tested.

\section{Results and Discussion}

\section{Synthesis of sorbitol-based polyesters using different catalysts}

For this study, the set of monomers has been selected to synthesize potentially fully bio-based polyesters. In fact, sorbitol and 1,3-propanediol (1,3-PD) are part of the "top twelve" building blocks produced from biomass via biological or chemical conversion. ${ }^{2}$ Recently also adipic acid has been synthesized from glucose ${ }^{9}$ making the dimethyl ester derivative close to be a potential bio-based monomer as well, provided that biomethanol is used for making this diester. Polyester polyols with molecular characteristics in a range commonly used for coating applications, with a relatively low molecular weight and a controlled type of reactive end-groups, i.e. hydroxyl groups, were aimed. By using the Carothers equation, based on the stoichiometric imbalance between sorbitol, 1,3-PD and dimethyl adipate, an estimate of the number-average molecular weight was calculated (see SI). For the synthesis of hydroxylterminated polyesters, an excess of hydroxyl with respect to the dimethyl ester groups is required. Thus, for the synthesis of poly(1,3-propylene-co-sorbitol adipate)s, the composition of the monomers was chosen as: sorbitol (5 mol\%), 1,3-PD (46 mol\%) and dimethyl adipate (49 mol\%). Benign and eco-friendly conditions such as in absence of solvent and low reaction temperature are desired, not only to reduce the energy consumption but, most importantly, to extend the possibility of using thermally unstable monomers such as sugars and sugarderivatives. In fact sorbitol is prone either to dehydrate at moderate temperature to hexitans (mainly giving 1,4-sorbitan and in minor amount 2,5-sorbitan) or, in presence of base- or acid-catalysts, even further to isosorbide (Scheme 1). ${ }^{7}$

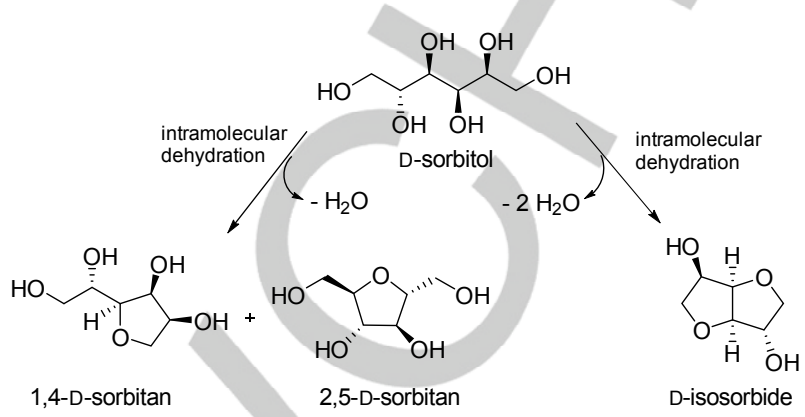

Scheme 1. Dehydration steps of sorbitol to sorbitan and isosorbide.

Four different catalysts have been selected for this comparative study regarding the synthesis of close to linear, hydroxylfunctional sorbitol-based polyesters: SPRIN liposorb CALB (immobilized form of Candida Antarctica lipase B), the organobase 1,5,7-triazabicyclo[4,4,0]dec-5-ene (TBD), and two metalbased catalysts, viz. scandium trifluoromethanesulfonate (also known as scandium triflate, $\left.\mathrm{Sc}(\mathrm{OTf})_{3}\right)$ and dibutyl tin oxide (DBTO) (Figure 1). In previous studies $\mathrm{Sc}(\mathrm{OTf})_{3}$ and CALB have shown high selectivity for primary over secondary hydroxyl groups. ${ }^{19,20}$ However, to the best of our knowledge, for TBD and DBTO no selectivity has been reported yet, and only the different kinetics for primary and secondary hydroxyl groups will play a role. ${ }^{21}$ It is worth to mention that the use of DBTO as catalyst in the polycondensation of glycerol and oleic diacid at $150{ }^{\circ} \mathrm{C}$ resulted in the formation of a gel due to cross-linking. ${ }^{11}$

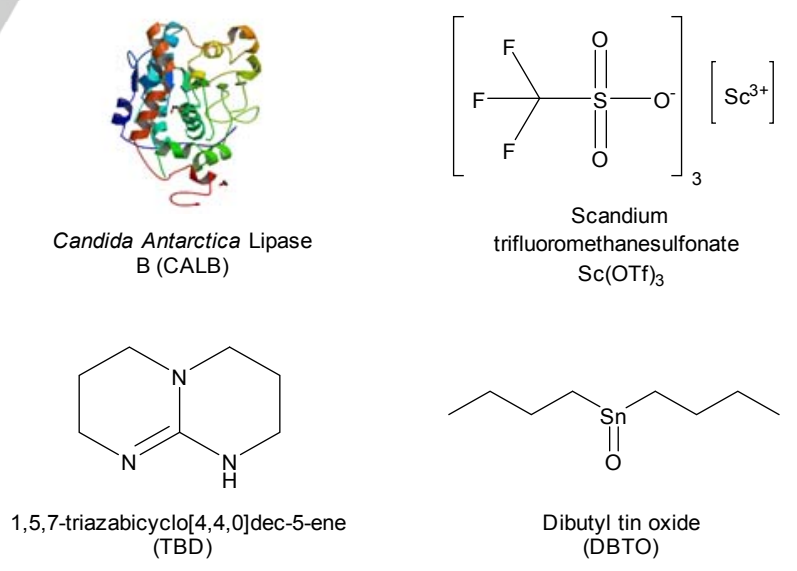

Figure 1. Chemical structure of CALB, $\mathrm{Sc}(\mathrm{OTf})_{3}$, TBD and DBTO catalysts.

For $\mathrm{Sc}(\mathrm{OTf})_{3}$, TBD and DBTO, the amount of catalyst chosen was $0.5 \mathrm{~mol} \%$, as commonly used in literature. ${ }^{10}$ Lipasecatalyzed polycondensation reactions performed using Novozyme 435 (an immobilized form of CALB) usually employ $10 \mathrm{wt} \%$ of immobilized biocatalyst compared to the total amount 
of monomers. ${ }^{29}$ When SPRIN liposorb CALB, a different immobilized form of CALB, is used as biocatalyst, the same catalytic activity as found for $10 \mathrm{wt} \%$ Novozyme 435 is obtained by using 7 wt $\%$ instead. ${ }^{22}$ Thus 7 wt $\%$ of SPRIN liposorb CALB with respect to the total amount of monomers was used in our study. The polymerization reaction conditions are depicted in Scheme 2. Through elemental analysis it was possible to estimate the $\mathrm{mol} \%$ of real enzyme catalyst that would correspond to $7 \mathrm{wt} \%$ of immobilized enzyme (detailed calculations can be found in the SI file). The immobilized form of SPRIN liposorb CALB consists of enzyme covalently immobilized on divinylbenzene (DVB)-cross-linked hydrophobic macroporous polymer based on methacrylic esters. Since the carrier does not contain nitrogen, the nitrogen content detected by elemental analysis corresponds solely to the enzyme molecules. The nitrogen content showed to be equal to $0.9 \mathrm{wt} \%$. Taking into account the primary structure of the enzyme, ${ }^{23}$ the amount of nitrogen per mole of enzyme was calculated. Thus, from these data, it was possible to determine the $\mathrm{mol} \%$ of enzyme actually corresponding to $7 \mathrm{wt} \%$ of biocatalyst used, being equal to $1.4 \cdot 10^{-3} \mathrm{~mol} \%$ with respect to the total amount of monomers. It is worth to emphasize that by this calculation it is assumed that all the nitrogen detected is coming from an active lipase. But, in fact, the enzymatic activity is not linearly related to the amount of enzyme found to be attached to the carrier. The immobilization procedure can cause inactivation of the enzyme, leading to a decrease of the final activity. ${ }^{24}$ Thus, even if the entire amount of enzyme attached to the cross-linked beads would be active, the mol\% of actual enzyme employed is two orders of magnitude lower than the other catalysts used. This result is remarkable concerning the high activity that the enzyme exhibits in comparison with the other catalysts (vide infra).<smiles>OC[C@H](O)[C@@H](O)[C@H](O)[C@H](O)CO</smiles>

sorbitol

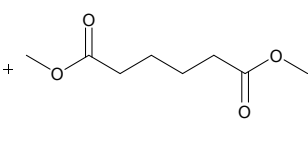

dimethyl adipate

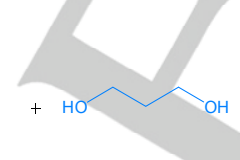

$60-140^{\circ} \mathrm{C}, \quad-$ SPRIN liposorb CALB

$$
\text { bulk, 26-103h, } \quad-\mathrm{Sc}(\mathrm{OTf})_{3}
$$
- DBTO

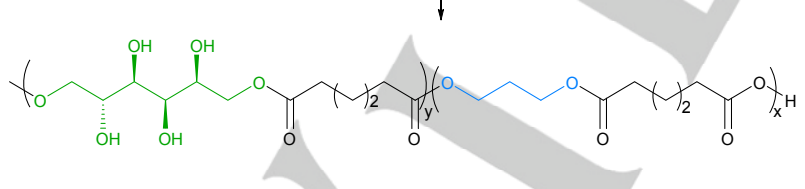

poly(1,3-propylene-co-sorbitol adipate)

Scheme 2. Schematic representation of the synthesis of poly(1,3-propyleneco-sorbitol adipate)s.

In our comparative study, two different sets of reactions have been carried out. In the first set, reactions were performed at the same temperature, aiming at comparing the catalysts performance under the same reaction conditions. This reaction temperature was selected to be $100{ }^{\circ} \mathrm{C}$, as low as possible to prevent thermal degradation of sorbitol and still maintain the activity of the enzyme, while keeping the monomers in the molten state (m.p. sorbitol $=95^{\circ} \mathrm{C}$ ). Under these conditions it is known that $\mathrm{Sc}(\mathrm{OTf})_{3}$ is able to catalyze reactions; also good performance of this catalyst has been reported for both higher and lower reaction temperatures. ${ }^{19}$ Regarding TBD and DBTO, polymerization reactions are usually carried out at higher temperatures, and a temperature of $100{ }^{\circ} \mathrm{C}$ may be not high enough for adequate active performance. ${ }^{15}$ For this reason, in the second set of experiments the reactions were performed at temperatures at which the selected catalysts are known to exhibit their optimum catalytic activity: $60^{\circ} \mathrm{C}$ for $\mathrm{Sc}(\mathrm{OTf})_{3},{ }^{11} 120$ ${ }^{\circ} \mathrm{C}$ for TBD, ${ }^{16}$ and $140{ }^{\circ} \mathrm{C}$ for DBTO. ${ }^{10}$

All polymerizations were performed in duplicate for all reaction conditions, and the molecular weights were followed by SEC measurements. Most polymerizations were stopped after 48 hours, when the desired molecular weights were reached. While for the majority of polymerizations good accordance between the polymer duplicates was obtained, both of them having similar appearance and being soluble in chloroform, reactions performed using DBTO catalyst at $140^{\circ} \mathrm{C}$ led to an insoluble gel in one duplicate experiment. Once this was observed, the other duplicate reaction was immediately stopped (reaction time: 26 hours) to perform the analysis of this soluble polymer before a gel would be formed (entry $\mathbf{g}$, Table 1 obtained as a soluble hard viscous clear material). With the non-selective DBTO catalyst, secondary hydroxyl groups of sorbitol may also be esterified, leading to cross-linking (vide infra). The color of the polyesters obtained varied from white to yellowish. When CALB was used as catalyst, a sticky white powder was obtained after precipitation (entries $\mathbf{a}$ and $\mathbf{h}$ ). Yellowish honey-like products were the result of the polymerizations using $\mathrm{Sc}(\mathrm{OTf})_{3}$ and TBD (entries b, $\mathbf{c}$ and $\mathbf{e}$ ). The molecular weight and polydispersity of the final polymers after precipitation were analyzed by SEC. The resulting sorbitol-based polyesters displayed number average molecular weights $\left(M_{n}\right)$ in the range between 1 and $13 \mathrm{~kg} / \mathrm{mol}$, with polydispersities (PDI) between 1.4 and 2.7 (Table 1). For those reactions carried out at $100{ }^{\circ} \mathrm{C}$ in presence of TBD or DBTO, only oligomers were formed within 48-72 hours of reaction, as expected. Only CALB showed to be able to build up the desired molecular weight at $100{ }^{\circ} \mathrm{C}$ within 48 hours of reaction time. Intermediate molecular weights were reached by using $\mathrm{Sc}(\mathrm{OTf})_{3}$ catalyst at the same temperature or at $60^{\circ} \mathrm{C}$. On the other hand, the reactions carried out by employing TBD at $120{ }^{\circ} \mathrm{C}$ showed a final $M_{\mathrm{n}}$ and PDI close to the values reached by CALB at $100^{\circ} \mathrm{C}$. 
Table 1. Feed ratio, final composition and molecular weights of sorbitol-containing polyesters prepared using different catalysts.

\begin{tabular}{|c|c|c|c|c|c|c|c|c|c|c|}
\hline & & & & Temperature & Time & Sorb. feed & Sork & & SEC & \\
\hline Entry & Monomers & Catalyst & $\mathrm{mol} \%$ & $\begin{array}{c}\text { reaction } \\
\left({ }^{\circ} \mathrm{C}\right)\end{array}$ & $\begin{array}{l}\text { reaction } \\
\text { (h) }\end{array}$ & $\begin{array}{l}\text { composition } \\
(\mathrm{mol} \%)\end{array}$ & $\begin{array}{l}\text { Incorporated } \\
(\mathrm{mol} \%)^{\mathrm{a}}\end{array}$ & $M_{\mathrm{n}}(\mathrm{kg} / \mathrm{mol})^{\mathrm{b}}$ & $\begin{array}{c}M_{\mathrm{n}} \\
(\mathrm{kg} / \mathrm{mol})^{\mathrm{c}}\end{array}$ & PDI \\
\hline a & \multirow{7}{*}{$\begin{array}{c}\text { DMA + } \\
\text { sorbitol } \\
+1,3-P D\end{array}$} & CALB & $1.4 \cdot 10^{-3}$ & 100 & 48 & 4.8 & 3.4 & 2.0 & 12.2 & 2.6 \\
\hline b & & $\mathrm{Sc}(\mathrm{OTf})_{3}$ & 0.5 & 100 & 48 & 5.2 & 2.5 & 2.0 & 4.8 & 1.8 \\
\hline c & & $\mathrm{Sc}(\mathrm{OTf})_{3}$ & 0.5 & 60 & 103 & 5.2 & 1.1 & 1.7 & 3.2 & 1.4 \\
\hline d & & TBD & 0.5 & 100 & 72 & 5.2 & n.d. & n.d. & $0.8^{\mathrm{d}}$ & $1.4^{\mathrm{d}}$ \\
\hline e & & TBD & 0.5 & 120 & 72 & 5.2 & 5.2 & 1.6 & 13.3 & 2.4 \\
\hline$f$ & & DBTO & 0.5 & 100 & 48 & 5.1 & n.d. & n.d. & $0.7^{d}$ & $1.2^{d}$ \\
\hline g & & DBTO & 0.5 & 140 & 26 & 5.2 & $4.0^{\mathrm{e}}$ & $1.5^{\mathrm{e}}$ & $10.5^{\mathrm{e}}$ & $2.7^{\mathrm{e}}$ \\
\hline $\mathbf{h}$ & $\begin{array}{c}\text { DMA } \\
+1,3-\mathrm{PD} \\
\end{array}$ & CALB & $1.4 \cdot 10^{-3}$ & 100 & 48 & 0 & 0 & & 5.2 & 2.1 \\
\hline
\end{tabular}

\section{Molecular characterization of sorbitol-based polyesters}

The molecular characterization of the polyesters is of great importance to evaluate the performance and the degree of selectivity of the catalysts for esterification of primary vs. secondary hydroxyl groups, the amount of sorbitol actually incorporated into the polyester backbone, as well as the occurrence of side reactions.

${ }^{13} \mathrm{C} N M R$. The obtained polymers were characterized through inverse-gated decoupling ${ }^{13} \mathrm{C}$ NMR, and the molar percentage of sorbitol incorporated into the polyester was calculated. It is assumed that residual monomers have been effectively removed through purification by precipitation from chloroform solution into methanol (monomeric sorbitol is well-soluble in methanol) and the sorbitol detected is truly implemented in the polymer chains.

1,3-PD units at the end of the polymer chain give rise to resonances at 32.8, 58.7 and $62.3 \mathrm{ppm}$. The appearance of a low-intensity peak at $51.7 \mathrm{ppm}$ in all spectra is assigned to the methoxy end group of the adipate unit, indicating that some adipate units are at the end of the polymer chain. For entries $\mathbf{b}$ and $\mathbf{c}$ the signal attributed to the methoxy end groups is comparably more intense than for other entries. On the other hand, the peak at $175 \mathrm{ppm}$, related to a carboxylic acid group, is present only when CALB is used as catalyst (entries $\mathbf{a}$ and $\mathbf{h}$, Table 1), indicating that some hydrolysis of the methyl ester groups occurs during the polymerization. However, for entries a, $\mathbf{e}, \mathbf{g}$ and $\mathbf{h}$, adipic/adipate end-groups were merely the minority and mostly hydroxyl end-capped polymers were obtained.

For entries $\mathbf{b}$ and $\mathbf{c}$, both involving $\mathrm{Sc}(\mathrm{OTf})_{3}$ catalyst, the spectra show three peaks at 29.8, 62.1 and $67.8 \mathrm{ppm}$, respectively, which are ascribed to dipropyleneglycol units (Figure 2). Thus, ether formation has been observed as side reaction for these two synthesis. Ether formation by the Lewis acid $\mathrm{Sc}(\mathrm{OTf})_{3}$ has been also reported for polycondensation reactions using 1,3-PD and methylsuccinic acid at $80{ }^{\circ} \mathrm{C} .{ }^{19}$ At $60{ }^{\circ} \mathrm{C}$ (entry c), $10 \%$ of the 1,3-PD units within the polymer chain (excluding end groups) are linked to another 1,3-PD unit by an ether linkage. When raising the temperature up to $100{ }^{\circ} \mathrm{C}$, this amount increases to $33 \%$ (entry $\mathbf{b}$ ).

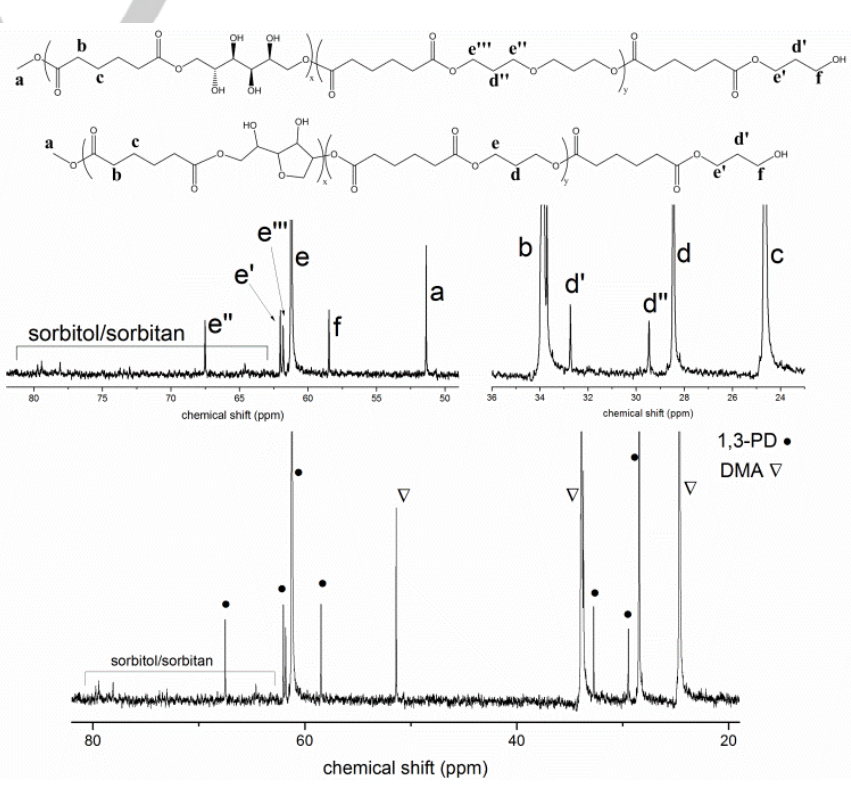

Figure 2. Section of inverse-gated decoupling ${ }^{13} \mathrm{C}$ NMR spectrum of poly(1,3propylene-co-sorbitol adipate) (entry c, Table 1 ) recorded in pyridine- $d_{5}$.

From the average integral values of all sorbitol resonances and the total integral values of all units, i.e. both chain end- and repeat-units, the molar percentage of sorbitol incorporated into the polyester was calculated. Looking at the region between 62.5 and $74 \mathrm{ppm}$ where the peaks of sorbitol arise, for each type of catalyst, a different number of signals is present. In case CALB is used as catalyst, only six peaks are present and it is possible to distinguish between carbons connected to primary (between 62.5 and $66 \mathrm{ppm}$ ) and secondary hydroxyl groups (between 67 and $74 \mathrm{ppm}$ ). If $\mathrm{Sc}(\mathrm{OTf})_{3}$ is employed as catalyst, more than six peaks are present and the region is extended till $80 \mathrm{ppm}$. In presence of a Lewis acid such as $\mathrm{Sc}(\mathrm{OTf})_{3}$, the 
sorbitol unit can be subjected to dehydration leading to the formation of sorbitan as side product. In fact, the resonance at $80 \mathrm{ppm}$ is due to the $-\mathrm{CH}$ of the five-membered ring of sorbitan. The absence of a signal at $85 \mathrm{ppm}$ excludes the presence of isosorbide. Regarding TBD and DBTO, more than six peaks are visible within the region between $62-75 \mathrm{ppm}$. A variety of ester linkages involving the sorbitol unit in the polymer chain, due to a different chemical environment, will result in a more complex NMR spectrum. The additional peaks could be also attributed to branching involving sorbitol residues. In the ESI, the spectra for entries a (CALB, $\left.100{ }^{\circ} \mathrm{C}\right)$ and $\mathbf{e}\left(\mathrm{TBD}, 120^{\circ} \mathrm{C}\right)$ are compared (Figure S1).

The data regarding the quantification of the actual incorporated amount of sorbitol (after precipitation in methanol) compared to the initial feed for the different catalysts is summarized in Table 1 and illustrated in Figure 3. For entry a, when using CALB at $100{ }^{\circ} \mathrm{C}$, an initial feed of $4.8 \mathrm{~mol} \%$ of sorbitol leads to an incorporated amount of $3.4 \mathrm{~mol} \%$ sorbitol into the polyester. In our prior work, the implementation of sorbitol in a relatively apolar polyester system, consisting of dimethyl adipate and 1,10-decanediol, was observed to be quite low. ${ }^{22}$ In fact, starting from $5 \mathrm{~mol} \%$ initial feed of sorbitol, due to the non-homogeneous mixture and lower affinity shown by CALB for sorbitol with respect 1,10 -decanediol, only $1.4 \mathrm{~mol} \%$ of sorbitol was found to be incorporated into the polyester. The use of a more polar diol such as 1,3-PD results in a homogeneous mixture which favors sorbitol implementation into the polyester.

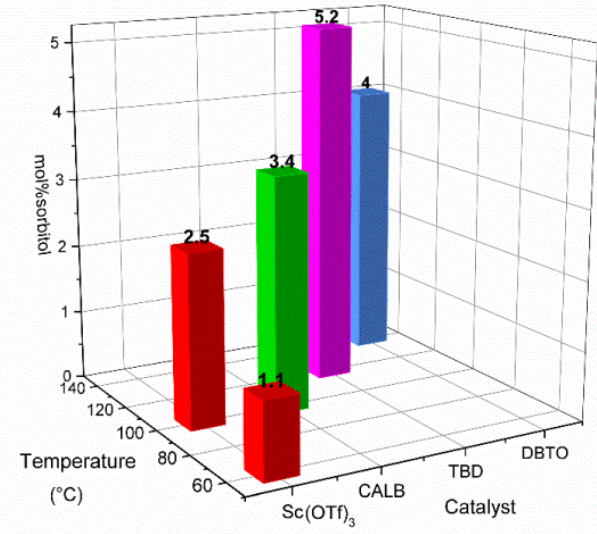

Figure 3. Amount of $\mathrm{mol} \%$ of sorbitol implemented at different reaction conditions. Initial feed mol\% of sorbitol: $4.8 \mathrm{~mol} \%$ (entry a) and $5.2 \mathrm{~mol} \%$ (entries b, c, e, g).

In presence of $\mathrm{Sc}(\mathrm{OTf})_{3}$, a low amount of sorbitol, i.e. $1.1 \mathrm{~mol} \%$, is incorporated at $60^{\circ} \mathrm{C}$ (entry c, Table 1). Although increasing the temperature to $100{ }^{\circ} \mathrm{C}$ allowed to implement more sorbitol into the chains (up to $2.5 \mathrm{~mol} \%$, entry b), it was observed that more ether linkages were formed as well (vide supra). This catalyst shows to produce mainly poly(ester ether)s instead of the desired polyester structure.
By using TBD as catalyst at $120^{\circ} \mathrm{C}$, almost full implementation of the initial sorbitol feed into the polyester was reached. The trend was followed by DBTO at $140{ }^{\circ} \mathrm{C}$ and CALB at $100{ }^{\circ} \mathrm{C}$, respectively. In these cases, no ether formation was detected. However the reactions with DBTO as catalyst performed at 140 ${ }^{\circ} \mathrm{C}$ only in one case led to an analyzable, soluble material, whereas a gel was obtained in the duplicate experiment. We suspect that the reason for such difference between the two duplicates is the lower conversion in the non-gelled case due to e.g. differences in the removal of methanol, which allowed to stay below the gelation point (detailed calculations in SI). Those conditions appear not to be reproducible for a standard protocol of polycondensation reactions involving sorbitol. It is worth to mention at this point that only in the case of CALB, six signals were present in the sorbitol ${ }^{13} \mathrm{C}$ NMR region, whereas additional peaks were found for $\mathrm{Sc}(\mathrm{OTf})_{3}, \mathrm{TBD}$ and DBTO. These additional peaks could be attributed either to sorbitan units or to branching involving sorbitol residues (vide supra).

The number average molecular weight $\left(M_{n}\right)$ was calculated from the obtained NMR spectra for all the synthesized polyesters (Table 1). An overestimation of the $M_{n}$ obtained via SEC measurements compared with the $M_{\mathrm{n}}$ obtained via ${ }^{13} \mathrm{C} N M R$ usually occurs for aliphatic polyesters, especially for $M_{\mathrm{n}}$ values lower than $10^{4} \mathrm{~g} / \mathrm{mol}^{25}$ Additionally, in this case the presence of sorbitol in the polymer chains and hydrogen-bonding between the chains can lead to higher hydrodynamic volumes (higher $M_{\mathrm{n}}$ SEC values). In fact, in the case of the homopolyester where no sorbitol is present (entry $\mathbf{h}$ ), the $M_{n}$ values obtained via ${ }^{13} \mathrm{C} \mathrm{NMR}$ and via SEC are more similar than in the case of the copolyesters. Moreover, the calibration is based on poly(methyl methacrylate) standards, which have a significantly different hydrodynamic volume compared to the polyester samples.

Potentiometric titration. By potentiometric titration it was possible to quantify the amount of $\mathrm{OH}$ - and $\mathrm{COOH}$ - groups present in the polyesters. Due to the presence of vicinal secondary hydroxyl groups in the sorbitol unit, the acylation time was extended from the usual $15 \mathrm{~min}$ to $50 \mathrm{~min}$ to guarantee the titration of all the different types of hydroxyl groups. As gathered in Table 2, the hydroxyl values (OHV) showed to be very high with respect to the acid values (AV). Such a big difference between OHV and $\mathrm{AV}$ reveals that the polyesters are mainly hydroxyl functionalized and that sorbitol is indeed present in the polyesters, confirming the NMR results. It also confirms that higher sorbitol content leads to higher OHV, as seen for entries $\mathbf{a}$, e and $\mathbf{g}$ in Table 2. Regarding the reactions where $\mathrm{Sc}(\mathrm{OTf})_{3}$ was used as catalyst (entries b and c, Table 2), a discrepancy between the OHV detected and the amount of sorbitol quantified via ${ }^{13} \mathrm{C}$ NMR is evident. This deviation can be related to the presence of ether linkages (thus less terminal hydroxyl groups and more methoxy end groups) originating from 1,3-PD units, increasing at higher temperature, in agreement with the data observed via NMR spectroscopy. A low AV is expected when starting from dimethyl ester rather than from dicarboxylic acid monomer. The detection of a certain value of acid is indicating that some hydrolysis occurred during the reactions, leading to a minority of $\mathrm{COOH}$ - 
Table 2. Acid (AV) and hydroxyl (OHV) values of the sorbitol-containing polyesters.

\begin{tabular}{|c|c|c|c|c|c|c|c|c|c|}
\hline \multirow[b]{2}{*}{ Entry } & \multirow[b]{2}{*}{ Monomers } & \multirow[b]{2}{*}{ Catalyst } & \multirow{2}{*}{$\begin{array}{l}\text { Temperature } \\
\text { Reaction } \\
\left({ }^{\circ} \mathrm{C}\right)\end{array}$} & \multirow{2}{*}{$\begin{array}{c}\text { Sorbitol } \\
\text { incorporated } \\
(\mathrm{mol} \%)\end{array}$} & \multicolumn{2}{|c|}{$\begin{array}{l}\text { Potentiometric } \\
\text { titration }\end{array}$} & \multicolumn{3}{|c|}{${ }^{31} \mathrm{P}$ NMR } \\
\hline & & & & & $\begin{array}{c}\mathrm{AV} \\
(\mathrm{mg} \\
\mathrm{KOH} / \mathrm{g})^{\mathrm{a}}\end{array}$ & $\begin{array}{c}\mathrm{OHV} \\
(\mathrm{mg} \\
\mathrm{KOH} / \mathrm{g})^{\mathrm{a}}\end{array}$ & $\begin{array}{c}\mathrm{AV} \\
(\mathrm{mg} \\
\mathrm{KOH} / \mathrm{g})^{\mathrm{b}}\end{array}$ & $\begin{array}{c}\mathrm{OHV} \\
(\mathrm{mg} \\
\mathrm{KOH} / \mathrm{g})^{\mathrm{b}}\end{array}$ & $\begin{array}{c}\text { Secondary } v s \\
\text { primary } \mathrm{OH} \\
\text { of sorbitol unit }\end{array}$ \\
\hline $\mathbf{a}$ & \multirow{5}{*}{$\begin{aligned} & \text { DMA } \\
&+ \text { sorbitol } \\
&+1,3-P D\end{aligned}$} & CALB & 100 & 3.4 & 4.8 & 123.8 & 1.5 & 85.9 & 5.7 \\
\hline b & & $\mathrm{Sc}(\mathrm{OTf})_{3}$ & 100 & 2.5 & 3.1 & 33.1 & 1.5 & 26.5 & 10.2 \\
\hline C & & $\mathrm{Sc}(\mathrm{OTf})_{3}$ & 60 & 1.1 & 1.9 & 45.4 & 1.5 & 35.9 & 32.0 \\
\hline e & & TBD & 120 & 5.2 & 3.4 & 140.5 & 1.4 & 108.2 & 7.7 \\
\hline g & & DBTO & 140 & 4.0 & 8.0 & 137.8 & 1.0 & 99.9 & 5.7 \\
\hline
\end{tabular}

end groups. Although the total amount of hydroxyl groups is of great value within this study, this method does not allow to distinguish between different types of hydroxyl groups (primary or secondary)

${ }^{31} P N M R$. The selectivity regarding the implementation of sorbitol into the backbone of the polyesters via its primary or secondary hydroxyl groups for the different catalysts was elucidated via ${ }^{31} \mathrm{P}$ NMR spectroscopy. As a spectroscopic technique, it is based on the different chemical environments of the observed nuclei, and is an effective method to evaluate different types of hydroxyl and carboxylic acid groups present in the polyester samples. Within this method, 2-chloro-4,4,5,5-tetramethyldioxaphospholane compound is made to react with the unreacted (primary and secondary) hydroxyl and carboxylic groups present on the obtained polyesters after precipitation in methanol. The derivatized polymer is then analyzed via ${ }^{31} \mathrm{P} N M R$, revealing whether the phospholane compound has reacted with a primary or a secondary hydroxyl group, or with a carboxylic acid group, which will all appear at different chemical shifts. By adding an internal standard, such as cyclohexanol, this method allows quantifying the amount of primary with respect to secondary hydroxyl groups as well as any carboxylic group present. ${ }^{32}$ Data afforded by the experiments are expressed in $\mathrm{mg} \mathrm{KOH} / \mathrm{g}$ sample in order to easily compare them with the potentiometric titration results (Table 2). In Figure S2 a representative spectrum is depicted, including assignment of the most relevant peaks after derivatization of the polyester with the phospholane compound. It is tempting to conclude that the presence of a peak at 174.9 $\mathrm{ppm}$, related to unreacted phospholane compound, points to a full derivatization of the hydroxyl and carboxylic end-groups. However, due to the bulkiness of the derivatizing compound, maybe not all hydroxyl and carboxylic acid end-groups are fully converted.

The possibility in distinguishing between unreacted primary and secondary hydroxyl groups due to different chemical shift allowed to evaluate the ratio between them. As shown in our previous study, ${ }^{22}$ if this ratio is higher than 4 , sorbitol is mostly implemented via its primary hydroxyl groups corroborating a selective esterification for the primary over the secondary hydroxyl groups of the sorbitol unit. As summarized in Table 2, when CALB, TBD and DBTO were employed (entries $\mathbf{a}, \mathbf{e}$ and $\mathbf{g}$ ), the ratio between secondary vs. primary hydroxyl groups showed to be in the same range, i.e. between 5.7 and 7.7, with a slightly higher value for TBD. These results indicate that, on average, the obtained polyesters are mostly linear. However, the discrepancies between the total OHV values determined by ${ }^{31} \mathrm{P}$ NMR and potentiometric titration suggest that not all hydroxyl groups present in the polyesters were fully converted to the phospholane derivative and thus have not been detected via ${ }^{31} \mathrm{P}$ NMR. Additionally, if sorbitan is present, it will contribute mostly with its three secondary hydroxyl groups to the total OHV rather than with the only primary one which most probably will be involved in the ester linkage. The comparably pronounced high values for secondary $\mathrm{OH}$ vs. primary $\mathrm{OH}$ ratio observed when employing $\mathrm{Sc}(\mathrm{OTf})_{3}$ as catalyst can be supported by the ${ }^{13} \mathrm{C}$ NMR measurements where signals associated to ether linkages were observed. Due to the fact that 1,3-PD is involved in the formation of ether-linkages, there are much less primary hydroxyl end-groups.

MALDI-ToF-MS. The copolyesters successfully obtained from the different reaction conditions (entries $\mathbf{a}, \mathbf{b}, \mathbf{c}, \mathbf{e}$ and $\mathbf{g}$ ) were studied by MALDI-ToF-MS. With this technique, the composition of individual polymer chains can be analyzed. Although this is not a quantitative analysis, it can provide relevant information regarding the distribution of the monomer residues over the polymer chains and the type of end-groups, and furthermore can elucidate the presence in some polymer chains of sorbitol as such or as its derivatives sorbitan or isosorbide. Two representative spectra are compared in Figure 4 

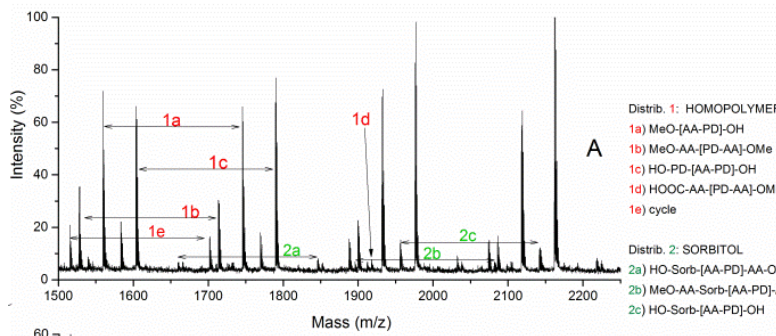
19) MeO-AAA.PDP-OH 1b) MeO-AA-[PD-AA]-OMe 1c) HO-PD-AAA-PDT-OH 1.) HOOC-AA-[PD-AA]-OM

Distrit 2. Sorsito 2a) HO-SOrb-AA-PD]-AA-OMe

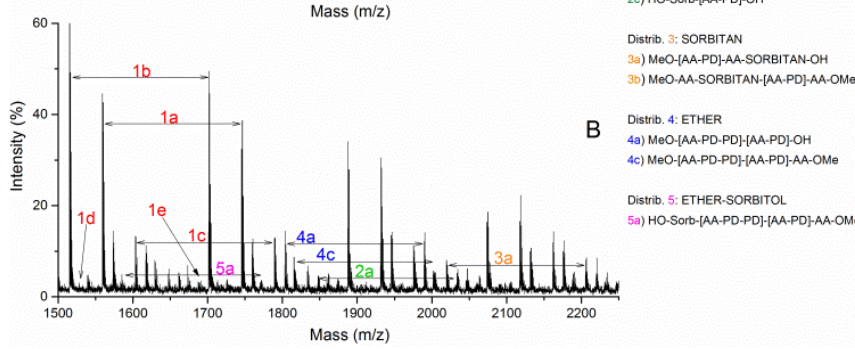

Figure 4. Section of MALDI-ToF-MS spectra of entries $\mathbf{a}(A)$ and $\mathbf{b}(B)$, signals cationized with $\mathrm{K}^{+}$or $\mathrm{H}^{+}$and related assignment of the distributions (AA: adipate; PD: 1,3-propanediol; Sorb: sorbitol).

Within this comparison of polycondensation reactions at different conditions, five main classes of distributions can be detected. The most intense distribution (distribution 1) is assigned to homopolymer chains, i.e. poly(1,3-propylene adipate), with no sorbitol present in the chain. For this composition, four different end-group possibilities were detected for all catalysts used: methoxy-hydroxyl (distribution 1a), methoxy-methoxy (distribution 1b), hydroxyl-hydroxyl (distribution 1c) and carboxylic acid-methoxy (distribution 1d). The presence of methoxy- or carboxylic acid-end groups confirmed that not fully hydroxyl end-capped polyesters have been synthesized despite the excess of diol used in the initial feed. Methoxy end-groups were minority in most of the ${ }^{13} \mathrm{C}$ NMR spectra, except for entries b and c. The presence of a carboxylic acid end group (distribution 1d) was in accordance with the detection of a certain AV value. Homopolymer cycles (distribution 1e) have also been detected for all the polymers, except when TBD was used (entry e, Table 1).

The second main distribution is related to polymer chains that contain sorbitol (distribution 2). Chains containing one sorbitol unit and having methoxy-hydroxyl end-groups were observed for all the different catalysts (distribution 2a). Also methoxy-methoxy end-groups (distribution $2 \mathrm{~b}$ ) were detected for entries $\mathbf{a}$ and $\mathbf{e}$, for chains containing one sorbitol residue. In this case sorbitol must be incorporated inside the polymer backbone. A distribution related to hydroxyl-hydroxyl (distribution 2c) terminated chains, containing also one sorbitol moiety, was observed for entries $\mathbf{a}$ and $\mathbf{g}$.

The third main distribution corresponds to sorbitan-containing chains (distribution 3), and it was observed for most of the polyesters, except when CALB was used as catalyst. Within this distribution containing one sorbitan residue, the methoxyhydroxyl (distribution 3a) end-group composition has been detected for entries $\mathbf{b}, \mathbf{c}, \mathbf{e}$ and $\mathbf{g}$, with an additional methoxymethoxy terminated composition (distribution $3 b$ ) when the reaction was catalyzed by TBD at $120{ }^{\circ} \mathrm{C}$ (entry e, Table 1) While via ${ }^{13} \mathrm{C}$ NMR the presence of sorbitan was only confirmed for the polymerizations using $\mathrm{Sc}(\mathrm{OTf})_{3}$, via MALDI-ToF-MS it was shown that also TBD and DBTO led to the formation and incorporation of sorbitan, although the quantities may be too small to be detected via ${ }^{13} \mathrm{C}$ NMR. The presence of isosorbide was not detected for any polymerization using any of the four different catalysts.

Two additional distributions were observed for the polymerizations catalyzed by $\mathrm{Sc}(\mathrm{OTf})_{3}$ (entries $\mathbf{b}$ and $\mathbf{c}$, Table 1). MALDI-ToF-MS analysis confirmed the formation of ether linkages as side reaction, as observed in the ${ }^{13} \mathrm{C}$ NMR spectra. In the first place, poly(ester ether)s containing no sorbitol but only 1,3-PD and adipate units (distribution 4) were detected with two or three 1,3-PD ether repeat units, having methoxy-hydroxyl (distribution 4a) or methoxy-methoxy (distribution 4c) endgroups. The last composition detected is related to poly(ester ether)s containing one sorbitol unit (distribution 5a), for both entries $\mathbf{b}$ and $\mathbf{c}$. In both cases, the polyester chains appeared to contain two or three 1,3-PD ether units and were methoxyhydroxyl terminated.

The important conclusion that can be drawn from this study is that sorbitol-containing chains are present in all polymers resulting from all the compared reaction conditions using all four different catalysts, but CALB is the only catalyst that allows incorporation of pure sorbitol and does not cause its degradation into sorbitan. 
Table 3. Thermal properties of sorbitol-containing polyesters.

TGA

DSC

\begin{tabular}{|c|c|c|c|c|c|c|c|c|c|c|}
\hline Entry & Monomers & Catalyst & $\begin{array}{c}\text { Reaction } \\
\text { Temperature } \\
\left({ }^{\circ} \mathrm{C}\right) \\
\end{array}$ & $\begin{array}{l}T_{5 \%}{ }^{a} \\
\left({ }^{\circ} \mathrm{C}\right)\end{array}$ & $\begin{array}{c}T_{\mathrm{d}}^{\mathrm{b}} \\
\left({ }^{\circ} \mathrm{C}\right)\end{array}$ & $\begin{array}{l}W^{c} \\
(\%)\end{array}$ & $\begin{array}{c}T_{g}{ }^{\mathrm{d}} \\
\left({ }^{\circ} \mathrm{C}\right)\end{array}$ & $\begin{array}{l}T_{C C}{ }^{d} \\
\left({ }^{\circ} \mathrm{C}\right)\end{array}$ & $\begin{array}{l}T_{m}^{d} \\
\left({ }^{\circ} \mathrm{C}\right)\end{array}$ & $\begin{array}{l}\Delta H_{m}{ }^{\mathrm{d}} \\
(\mathrm{J} / \mathrm{g})\end{array}$ \\
\hline $\mathbf{a}$ & \multirow{5}{*}{$\begin{array}{c}\text { DMA + } \\
\text { sorbitol +1,3- } \\
\text { PD }\end{array}$} & CALB & 100 & 342 & 405 & 1 & -48 & - & - & - \\
\hline b & & $\mathrm{Sc}(\mathrm{OTf})_{3}$ & 100 & 303 & 385 & 2 & -52 & - & - & - \\
\hline c & & $\mathrm{Sc}(\mathrm{OTf})_{3}$ & 60 & 315 & 374 & 1 & -57 & -1 & $21 / 31$ & $16 / 4$ \\
\hline e & & TBD & 120 & 298 & 406 & 1 & -49 & - & - & - \\
\hline g & & DBTO & 140 & 266 & 337 & 6 & -49 & - & - & - \\
\hline $\mathbf{h}$ & $D M A+1,3-P D$ & CALB & 100 & 327 & 401 & 0 & -59 & $-21 / 10$ & $29 / 38$ & $50 / 4$ \\
\hline
\end{tabular}

DMA = dimethyl adipate; 1,3-PD $=1,3$-propanediol; ${ }^{a}:$ Temperature at which $5 \%$ weight loss was observed; ${ }^{\mathrm{b}}:$ Temperature for maximum degradation rate; ${ }^{\mathrm{C}}$ : Remaining weight at $600^{\circ} \mathrm{C}$; ${ }^{d}$ : Transitions temperatures and melting enthalpies determined from the second heating curve of the DSC thermogram at a heating rate of $10^{\circ} \mathrm{C} / \mathrm{min}: T_{\mathrm{g}}$ : glass transition temperature, $T_{\mathrm{cc}}$ : cold crystallization temperature, $T_{\mathrm{m}}$ : melting temperature and $\Delta H_{m}:$ melting enthalpy.

\section{Thermal properties of sorbitol-based polyesters}

The thermal properties of the synthesized polyesters were determined by thermogravimetric analysis (TGA) and differential scanning calorimetry (DSC). The thermal parameters resulting from these analyses are summarized in Table 3.

The thermal stability was evaluated under an inert atmosphere by TGA. The TGA traces of the whole set of poly(1,3-propyleneco-sorbitol adipate)s, with the homopolyester poly(1,3-propylene adipate) for comparison, are depicted in Figure 5. The thermal decomposition of the polyesters occurs mostly in a single stage with a maximum decomposition rate $\left(T_{\mathrm{d}}\right)$ between of $330^{\circ} \mathrm{C}$ and $410{ }^{\circ} \mathrm{C}$. The lowest thermal stability is observed when DBTO was employed as catalyst at $140{ }^{\circ} \mathrm{C}$, and the residual weight left upon heating at $600{ }^{\circ} \mathrm{C}$ is $6 \%$. For all the other copolyesters, the residual weight is only $0-2 \%$. From this comparative thermogravimetric study it appears that the sorbitol-based copolyester synthesized via enzymatic catalysis (entry a, Table 3) and the one synthesized using TBD (entry e, Table 3) show the highest thermal stability with respect to the others, being also comparable to the homopolyester synthesized by the enzymatic approach (entry $\mathbf{h}$, Table 3 ). DSC data of polyesters are reported in Figure 6. A heating-cooling cycle was performed from -80 to $120{ }^{\circ} \mathrm{C}$ in order to erase the thermal history. The homopolyester poly(1,3-propylene adipate) (entry $\mathbf{h}$ ), synthesized using CALB at $100{ }^{\circ} \mathrm{C}$, showed to be a semicrystalline material as reported in literature, ${ }^{17,26}$ with $T_{\mathrm{g}}$ at $-59^{\circ} \mathrm{C}$. Although differences in the synthetic protocol and molecular weights can preclude a direct comparison, similar thermal transitions are observed. The poly(ester ether) synthesized by using $\mathrm{Sc}(\mathrm{OTf})_{3}$ at $60{ }^{\circ} \mathrm{C}$ (entry c) gives heating traces comparable to the homopolyester. Although for the homopolyester two distinct (cold) crystallization exotherms were observed at -21 and $10{ }^{\circ} \mathrm{C}$ during the second heating run, for entry $\mathbf{c}$ a single broad peak covering the same region with a lower enthalpy can be observed.

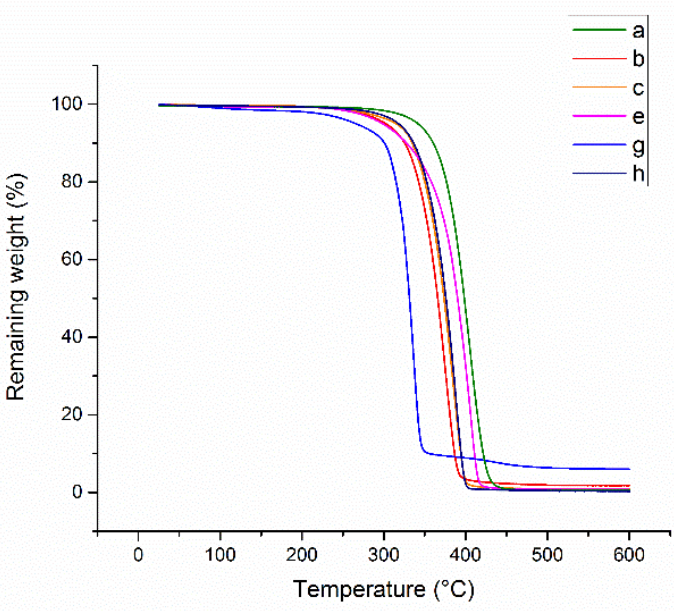

Figure 5. TGA thermograms obtained for the synthesized polyesters listed in Table 1.

The bimodal melting peaks present for the homopolyester are also observed for entry c, indicating that two different crystal populations are present in both cases, but with lower degree of crystallinity in the case of the poly(ester ether). The sorbitolbased copolyesters from entries $\mathbf{a}, \mathbf{b}, \mathbf{e}$ and $\mathbf{g}$ are amorphous materials with glass transition temperatures $\left(T_{\mathrm{g}}\right)$ around $-50{ }^{\circ} \mathrm{C}$. From these data, it appears that the sorbitol/sorbitan units present in the polymer chains are capable of interfering with the ability of polymers to crystallize. Also a slightly increased value of the $T_{\mathrm{g}}$ with respect to the homopolyester is observed, most likely due to some hydrogen bond formation involving the sorbitol residues. 


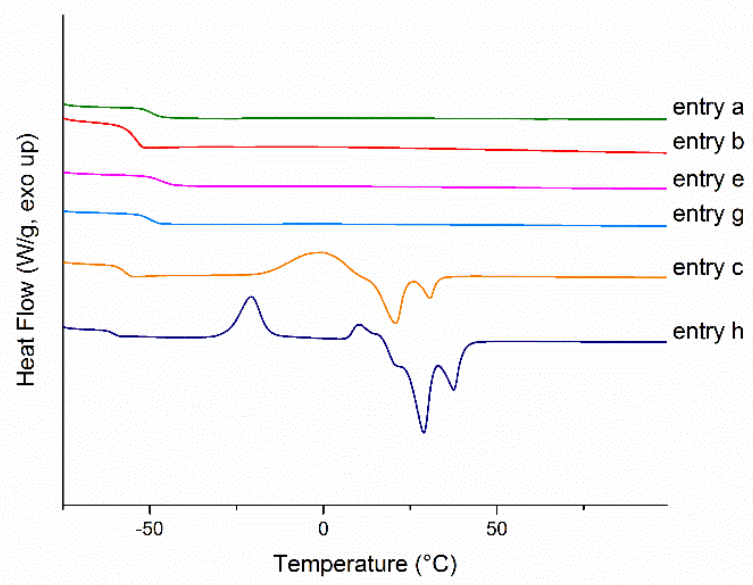

Figure 6. DSC traces from the second heating run of the copolyesters (entries $\mathbf{a}, \mathbf{b}, \mathbf{c}, \mathbf{e}$ and $\mathbf{g}$ ) and the homopolymer (entry $\mathbf{h}$ ). The experiments were carried out from -80 to $100{ }^{\circ} \mathrm{C}$ at a heating rate of $10^{\circ} \mathrm{C} / \mathrm{min}$.

\section{Curing and coating evaluation of sorbitol-based polyesters}

The sorbitol-based amorphous polyester synthesized using CALB (entry a) was further used to prepare coatings, since it displayed an $M_{\mathrm{n}}$ and hydroxyl functionality adequate to be employed as polyester polyol for the synthesis of a polyesterurethane network. Recent studies have reported a range of polyurethanes derived from bio-based L-lysine diisocyanate (LDI) to be biodegradable, non-toxic, and suitable to be used in biomedical applications, especially in drug delivery. ${ }^{27}$ In our work preliminary tests on solvent-cast coatings were carried out after using a conventional petroleum-based polyisocyanate curing agent, known as Desmodur N3600 (trade name for an isocyanurate trimer of hexamethylene diisocyanate, cross-linker I, Scheme 3) and after using the bio-based ethyl ester L-lysine diisocyanate (EELDI, cross-linker II, Scheme 3). Since some petroleum-based compounds are inevitable for the synthesis of the isocyanate functionality, ${ }^{28}$ the renewable content of EELDI is $75 \mathrm{wt} \%$.

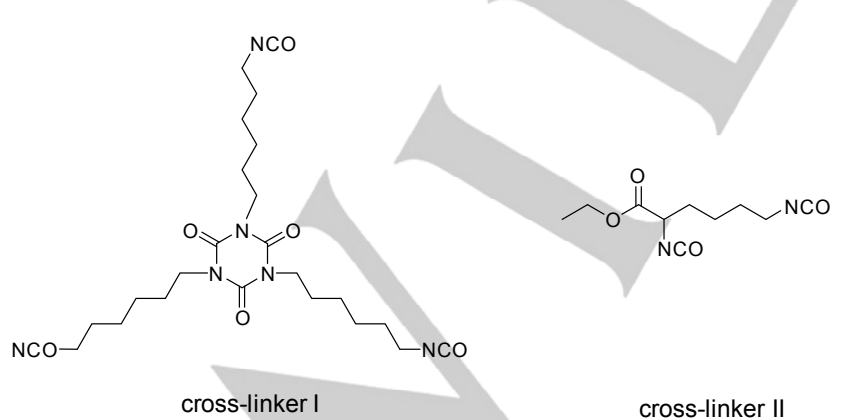

Scheme 3. Cross-linker I (Desmodur N3600) and cross-linker II (EELDI).
Table 4 lists the properties of the resulting poly(ester urethane) coatings. The amount of the curing agent was calculated to have a ratio $\mathrm{OH}: \mathrm{NCO}=1: 1$, based on the $\mathrm{OH}$-value determined via potentiometric titration. The poly(ester urethane) networks obtained upon curing of the polyester polyol/cross-linker mixtures onto the aluminum Q-panel substrates resulted in transparent, glossy and slightly yellowish homogeneous films. Both films showed good chemical resistance (i.e. acetone resistance test) and moderate mechanical performance (i.e. impact resistance and hardness). In fact, small defects such as dewetting of the substrate or non-homogeneous thickness of the films showed to affect the ability to resist rapid deformations. Both films presented intermediate hardness, F1 being slightly harder due to the more rigid structure of the cross-linker employed.

Free standing films were obtained by mixing the sorbitol-based polyester and the curing agent in $\mathrm{CHCl}_{3}$, applying the solution in a Petri-dish, drying it at $80^{\circ} \mathrm{C}$ under argon, and curing it at 180 ${ }^{\circ} \mathrm{C}$ under argon flow. The Petri-dish was previously treated with chlorotrimethylsilane to reduce its hydrophilicity and to facilitate the removal of the film prior to the DMTA examination. The yellowish color of EELDI cross-linker itself, together with the adopted curing conditions, led to a yellowish, transparent and glossy film (Figure S3). A colorless, transparent and glossy film was obtained when Desmodur N3600 was used (Figure S3). Via dynamic mechanical thermal analysis (DMTA), the thermomechanical properties of the free standing films were analyzed. The free standing films showed to be fully crosslinked, with $T_{\mathrm{g}}$ of $6{ }^{\circ} \mathrm{C}$ and $-16{ }^{\circ} \mathrm{C}$ when cross-linkers I and II were used, respectively. As expected, the $T_{\mathrm{g}}$ of the obtained cross-linked poly(ester urethane)s are higher than the $T_{\mathrm{g}}$ of the starting resin. The pronounced difference in $T_{\mathrm{g}}$ between the two cured networks can be attributed to the different chemical structure of the curing agents. The more rigid Desmodur N3600 leads to higher $T_{\mathrm{g}}$ with respect to the linear EELDI. The DMTA profile for F2 (Figure 7) showed a relatively narrow tan $\delta$ which is an indication of a quite homogeneous network. Furthermore, the increase of the storage modulus above $T_{\mathrm{g}}$ is an indication of efficient cross-linking. By combining a cross-linker derived from the natural amino acid L-lysine (its ethyl ester EELDI) with the fully bio-based polyester polyol $\mathbf{a}$, it was possible to prepare an aliphatic network with $95 \mathrm{wt} \%$ renewable content that showed to be suitable for coating applications.

\section{Cross-linker I (Desmodur N3600) and cross-linker II (EELDI).}


Table 4. Properties of poly(ester urethane)s obtained from sorbitol-based polyester (entry a, Table 1) with cross-linkers I and II.

\begin{tabular}{|c|c|c|c|c|c|c|c|c|c|}
\hline Resin & Film & $\begin{array}{l}\text { Curing } \\
\text { agent }^{\mathrm{a}}\end{array}$ & $\begin{array}{c}\text { Renewability } \\
\text { wt\% }\end{array}$ & $\begin{array}{c}\text { Ratio } \\
\mathrm{OH}: \mathrm{NCO}\end{array}$ & $\begin{array}{c}\text { Acetone } \\
\text { resistance }^{\mathrm{b}} \\
\text { [d.r. 100] }\end{array}$ & $\begin{array}{l}\text { Impact test }^{\mathrm{b}} \\
{[1 \mathrm{~kg}, 90 \mathrm{~cm}]}\end{array}$ & $\begin{array}{c}\text { Av. Film } \\
\text { thickness } \\
{[\mu \mathrm{m}]}\end{array}$ & $\begin{array}{c}\text { Pencil } \\
\text { hardness }^{c}\end{array}$ & $\begin{array}{l}T_{\mathrm{g}}^{\mathrm{d}} \\
\left({ }^{\circ} \mathrm{C}\right)\end{array}$ \\
\hline \multirow{2}{*}{ a } & $\mathrm{F} 1$ & I & 71 & $1: 1$ & + & $+/-$ & 30 & $2 \mathrm{H}$ & 6 \\
\hline & $\mathrm{F} 2$ & II & 95 & $1: 1$ & + & $+/-$ & 28 & $2 B$ & -16 \\
\hline
\end{tabular}

a: I: Desmodur N3600; II: EELDI. ${ }^{b}:+=$ good, $\pm=$ moderate and $-=$ poor. ${ }^{c}: 6 \mathrm{H}$ to $2 \mathrm{H}=$ very hard to hard, $\mathrm{H}$ to $\mathrm{B}=$ moderate hard, $2 \mathrm{~B}$ to $6 \mathrm{~B}=$ soft to very soft. ${ }^{\mathrm{d}}$ : From DMTA measurement of the cured material.

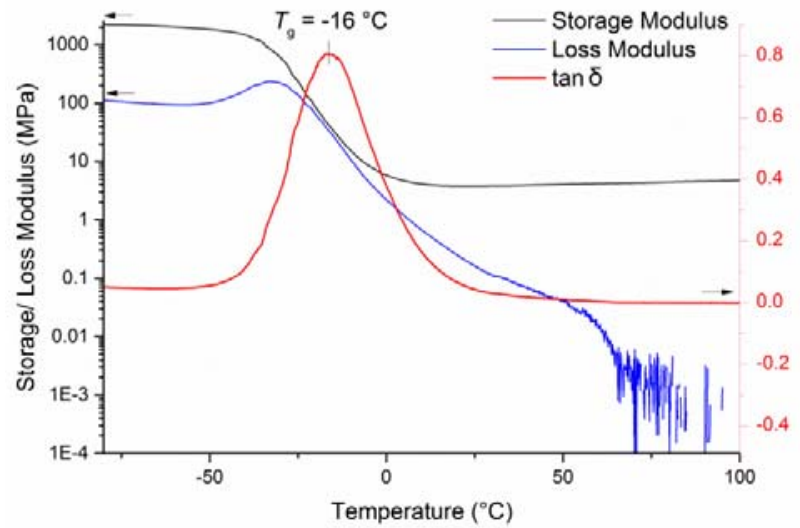

Figure 7. DMTA trace of the storage and loss modulus (black and blue lines) and the related $\tan \delta$ (red line) for $\mathrm{F} 2$. The $T_{\mathrm{g}}$ is determined as the maximum of the $\tan \delta$. The increase of the storage modulus above $T_{\mathrm{g}}$ is an indication of efficient cross-linking.

\section{Conclusions}

Four different catalytic systems were screened toward the implementation of the thermally sensitive, multifunctional sorbitol monomer in the synthesis of hydroxyl-functional, bio-based polyesters via melt polycondensation. DBTO-catalyzed polycondensation at $140{ }^{\circ} \mathrm{C}$ proved to have limitations in providing a soluble polymer with the targeted molecular weights, while no polymerization was observed at milder conditions, i.e. $100{ }^{\circ} \mathrm{C}$. When the reacting mixture at $140{ }^{\circ} \mathrm{C}$ was stopped before gelation, it was shown that the conditions were also too severe to leave the thermally sensitive sorbitol intact, leading to the formation of sorbitan as side reaction product. In case $\mathrm{Sc}(\mathrm{OTf})_{3}$ was used as catalyst, mostly poly(ester ether)s were obtained as final products, and the formation of ether linkages was promoted when increasing the temperature from 60 to $100{ }^{\circ} \mathrm{C}$. Moreover, $\mathrm{Sc}(\mathrm{OTf})_{3}$ also favored the dehydration of sorbitol to sorbitan. When the organo-base TBD was employed as catalyst, no polymerization was observed at $100{ }^{\circ} \mathrm{C}$, and a minimum temperature of $120^{\circ} \mathrm{C}$ was needed to provide the targeted molecular weights. Although these reaction conditions showed the highest ability of implementing sorbitol into the polymer chains with respect to the other catalysts, some sorbitol was degraded to sorbitan, revealing that this route was also unsuccessful in maintaining the sorbitol unit fully intact. Despite providing a slightly lower amount of sorbitol incorporated with respect to TBD, the use of SPRIN liposorb CALB at $100^{\circ} \mathrm{C}$ was proven to give the most suitable approach for the synthesis of polyesters with preserved sorbitol units. With the use of SPRIN liposorb CALB, side reactions such as degradation to sorbitan or ether formation were avoided. Moreover, the high efficiency shown by SPRIN liposorb CALB in the synthesis of polyesters, with respect to the other catalysts used in this study, is highly remarkable, the catalytic amount being two orders of magnitude lower with respect to the three other catalysts. This sustainable synthetic route resulted in sorbitol-based, mainly hydroxylfunctionalized amorphous polyesters with enhanced functionalities, i.e. pendant hydroxyl groups, adequate for coatings applications. When the bio-based hydroxyl-reactive, diisocyanate curing agent EELDI was used, the obtained yellow transparent poly(ester urethane) coating displayed homogeneous cross-linking and satisfactory chemical and mechanical properties. A tangible example of sustainable polymer chemistry and catalysis has been shown: from biobased monomers through an (enzymatic) eco-friendly, solventfree approach towards the development of close to fully renewable materials.

\section{Experimental Section}

\section{Materials}

Sorbitol was obtained as a gift from Roquette (NeosorbP6 Sorbitol, 98\%). 1,3-propanediol (1,3-PD, 98\%), dimethyl adipate (DMA, >99\%), acetic anhydride (>99\%), chromium (III) acetylacetonate $\left(\mathrm{Cr}(\mathrm{acac})_{3}, 99.99 \%\right), 2$ chloro-4,4,5,5-tetramethyldioxaphospholane (95\%), scandium trifluoromethanesulfonate $\left(\mathrm{Sc}(\mathrm{OTf})_{3}, 99.995 \%\right)$, triazobiciclodecene (TBD, $98 \%$ ), dibutyl tin (IV) oxide (DBTO, 98\%), chlorotrimethylsilane (>99\%) and an $0.1-0.5 \mathrm{~N}$ methanolic solution of $\mathrm{KOH}$ were obtained from SigmaAldrich. All solvents were purchased from Biosolve and all chemicals were used as received. Chloroform- $d\left(99.8 \%\right.$ atom- $d$ ) and pyridine- $d_{5}$ $(99.5 \%$ atom- $d$ ) were obtained from Cambridge Isotope Laboratories Ethyl ester L-lysine diisocyanate (EELDI, 95\% pure) was supplied by Infine Chemicals Co., Limited, China. The isocyanurate trimer of hexamethylene diisocyanate (Desmodur N3600) was a kind gift from Bayer AG. The polyisocyanates were kept in the fridge at $4{ }^{\circ} \mathrm{C}$ under argon. SPRIN liposorb CALB (Candida antarctica lipase B, immobilized on beads of a divinylbenzene (DVB)-cross-linked, hydrophobic, macroporous polymer based on methacrylic esters), was purchased from SPRIN S.p.a. and stored in a refrigerator at $4{ }^{\circ} \mathrm{C}$. Like sorbitol, the biocatalyst was dried before use at room temperature under reduced pressure for $24 \mathrm{~h}$ following a literature procedure. ${ }^{29}$

\section{Synthesis of poly(1,3-propylene-co-sorbitol adipate)s}

In a $300 \mathrm{~mL}$ three neck round bottom flask flange reactor with a magnetically coupled anchor stirrer, 1,3-PD, sorbitol and DMA were melted at $105{ }^{\circ} \mathrm{C}$. When a clear reaction mixture was obtained, the catalyst ( $7 \mathrm{wt} \%$ of SPRIN liposorb CALB or $0.5 \mathrm{~mol} \%$ of Sc(OTf) $)_{3}$, TBD or DBTO with respect to the total amount of monomers) was added to the reaction, and the temperature was set to a selected value between 60 and $140{ }^{\circ} \mathrm{C}$. The reaction mixture was stirred at $130 \mathrm{rpm}$ for $2 \mathrm{~h}$ under a constant argon flow, aiding the produced condensate methanol to pass 
over a vigreux column and to condensate in a Dean-Stark apparatus. After the pre-polymerization step, the reaction was continued under reduced pressure descending from 250 mbar to 50 mbar over $4 \mathrm{~h}$, and subsequently was continued at 50 mbar till the end of the polymerization. After that time, the vessel was cooled down to room temperature at atmospheric pressure and the reaction was quenched by adding approx. $50 \mathrm{~mL}$ of chloroform. The resulting mixture was filtered through a glass filter (pore size 1) to separate the crude product solution from the enzyme beads. Further workup included the precipitation of this solution in cold methanol. Entries $\mathbf{d}$ and $\mathbf{f}$ were not precipitated in methanol due to their low molecular weights. In the case of entries $\mathbf{a}$ and $\mathbf{h}$ (Table 1 , vide infra), the white suspension obtained after precipitation was filtered over a glass filter (pore size 4) and the product was isolated as a white sticky powder and dried under reduced pressure at $25{ }^{\circ} \mathrm{C}$ overnight. Concerning entries $\mathbf{b}, \mathbf{c}, \mathbf{e}$ and $\mathbf{g}$, the mixture obtained after precipitation into cold methanol appeared to be a viscous sticky honey-like material residing at the bottom of the flask. Thus, by decantation, the methanol was removed gently and the final sticky product was died under reduced pressure for 3 days at $25^{\circ} \mathrm{C}$. Regarding entries b, $\mathbf{c}$ and e (Table 1), the final products appeared to be yellowish sticky honey-like materials or, for entry $\mathbf{g}$ (Table 1), a hard viscous clear material.

\section{Preparation of solvent-borne coatings}

The hydroxyl-functional sorbitol-based polyesters were cured using two different poly- and di-isocyanates: i) a trimer of hexamethylene diisocyanate (trifunctional polyisocyanate, $\mathrm{NCO}$ equivalent weight $=183$ $\mathrm{g} / \mathrm{mol}$, known as Desmodur N3600), and ii) the ethyl ester of L-lysine diisocyanate (difunctional polyisocyanate, NCO equivalent weight $=113$ $\mathrm{g} / \mathrm{mol}$, EELDI). A solution of $0.2 \mathrm{~g}$ of the sorbitol-based polyester in 0.5 $\mathrm{mL}$ of $\mathrm{N}$-methyl-2-pyrrolidone was prepared and added to the isocyanate (1:1 equivalent ratio of $\mathrm{NCO}$ relative to the amount of $\mathrm{OH}$-groups present in the sample as determined by potentiometric titration). The obtained two-component mixture was then applied onto an aluminum Q-panel with a wet film thickness of $160 \mu \mathrm{m}$ using an adjustable doctor blade. The films were dried at $80{ }^{\circ} \mathrm{C}$ under argon, and cured at $180{ }^{\circ} \mathrm{C}$ under argon for $30 \mathrm{~min}$. These coatings were tested for hardness, reverse impact resistance and solvent resistance. The free standing films for DMTA measurements were prepared by solubilizing $0.2 \mathrm{~g}$ of sorbitol-based polyester in $0.3 \mathrm{~mL}$ of chloroform and subsequently dissolving the curing agent. Via a syringe, the solution was applied on a Petri dish pre-treated with chlorotrimethylsilane, which was used to reduce the hydrophilicity of the substrate and facilitate the removal of the film. The wet films were dried at $80^{\circ} \mathrm{C}$ under argon, and cured at $180^{\circ} \mathrm{C}$ under argon atmosphere for $30 \mathrm{~min}$.

\section{Characterization}

Potentiometric titration. The acid value (AV) was determined by direct potentiometric titration with a methanolic $\mathrm{KOH}$ solution, and the hydroxyl value $(\mathrm{OHV})$ was determined following the standard test methods for hydroxyl group determination (ASTM E222-10). ${ }^{30}$ A precise description of the methods to calculate AV and OHV is reported in the SI.

Size exclusion chromatography (SEC). SEC in 1,1,1,3,3,3hexafluoroisopropanol (HFIP) was performed on a system equipped with a Waters 1515 Isocratic HPLC pump, a Waters 2414 refractive index detector $\left(35^{\circ} \mathrm{C}\right)$, a Waters 2707 auto sampler, and a PSS PFG guard column followed by two PFG-linear-XL $(7 \mu \mathrm{m}, 8 \times 300 \mathrm{~mm})$ columns in series at $40{ }^{\circ} \mathrm{C}$. HFIP with potassium trifluoroacetate $(3 \mathrm{~g} / \mathrm{L})$ was used as eluent at a flow rate of $0.8 \mathrm{~mL} / \mathrm{min}$. Before SEC analysis was performed, the dissolved samples were filtered through a $0.2 \mu \mathrm{m}$ PTFE filter. The molecular weights were calculated against poly(methyl methacrylate) standards (Polymer Laboratories, $M_{p}=580$ Da up to $M_{p}=7.1 \times 10^{6} \mathrm{Da}$ ).
Elemental analysis. Elemental analysis was performed on a PerkinElmer CHNS/O Elemental Analyzer (2400 Series II) coupled with a PerkinElmer AD-4 Autobalance. Inside the system, a $\mathrm{CHN}$ combustion tube (operational temperature at $925{ }^{\circ} \mathrm{C}$ ) and a $\mathrm{CHN}$ reduction tube (operational temperature at $640{ }^{\circ} \mathrm{C}$ ) were installed. Only $\mathrm{C}, \mathrm{H}$ and $\mathrm{N}$ could be determined. Around 1.5 - $2.5 \mathrm{mg}$ of enzyme beads were weighted in a tin capsule on the AD-4 Autobalance and then moved into the furnace. The carrier gas used was helium while the combustion gas was oxygen. The separation and detection of the combusted gas were performed respectively by using a frontal chromatography separation technique coupled with a TCD (Thermal Conductivity Detector).

Carbon nuclear magnetic resonance $\left({ }^{13} \mathrm{C} N M R\right)$. Quantitative ${ }^{13} \mathrm{C}$ NMR spectroscopy was performed on a Bruker AMX-300 spectrometer at $25.0^{\circ} \mathrm{C}$, operating at $75.5 \mathrm{MHz}$ using an inverse gated decoupling pulse sequence to avoid nOe enhancement of the ${ }^{13} \mathrm{C}$ NMR signals. Around 15000 scans were acquired with $64 \mathrm{~K}$ data points and a relaxation delay of $3 \mathrm{~s}$. The spectral width was $22727 \mathrm{~Hz}$ and the number of data points for the FID was $32 \mathrm{~K}$. Samples were prepared by dissolving $40-50 \mathrm{mg}$ of the crude polymer in $0.5 \mathrm{~mL}$ pyridine- $d_{5}$ and adding and $\mathrm{Cr}(\mathrm{acac})_{3}(0.025$ $\mathrm{M})^{31}$ as a spin relaxation agent. Chemical shifts are reported in ppm relative to the residual peak of pyridine- $d_{5}(\delta=135.91 \mathrm{ppm})$. Data analysis was performed using Mestrec 4 software.

Phosphorus nuclear magnetic resonance $\left({ }^{31} \mathrm{P} \quad \mathrm{NMR}\right) .{ }^{31} \mathrm{P} \quad \mathrm{NMR}$ spectroscopy was performed on a Varian Unity Inova 500 spectrometer at a resonance frequency of $202.34 \mathrm{MHz}$. The spectral width of the experiments was $53569.79 \mathrm{~Hz}$. The delay time was set at $3 \mathrm{~s}$ with a number of recorded scans of 1024 . Sample preparation was carried out following a literature procedure. ${ }^{32} \mathrm{~A}$ stock solution was prepared by weighing exactly $530 \mathrm{mg} \mathrm{Cr}(\mathrm{acac})_{3}(30.3 \mathrm{mM})$ and $150 \mathrm{mg}$ cyclohexanol (30 mM) in a $50 \mathrm{~mL}$ volumetric flask. These compounds were subsequently dissolved in a mixture of pyridine and $\mathrm{CDCl}_{3}$ (2.3:1 volume ratio). $4 \AA$ molecular sieves were added to protect the stock solution from moisture. Cyclohexanol was used as an internal standard for quantification purposes. Around $45-50 \mathrm{mg}$ of the polymer were accurately weighed into a vial, $0.6 \mathrm{~mL}$ of stock solution was added and the solution was transferred to a $5 \mathrm{~mm}$ NMR tube. Subsequently, $70 \mu \mathrm{L}$ of phospholane reagent was added and $\mathrm{HCl}$ gas was formed, indicating that the phosphorylation reaction took place. The reaction mixture was left to react for about $30 \mathrm{~min}$ at room temperature. Upon completion of the reaction, after the $\mathrm{HCL}$ formation had stopped, the solution was used to obtain the ${ }^{31} \mathrm{P}$ NMR spectra. Chemical shifts are reported in ppm relative to the residual peak of water-derivatized phospholane $(\delta=132.2 \mathrm{ppm})$. Data analysis was performed using Mestrec 4 software.

Thermogravimetric analysis (TGA). TGA was performed using a TA Instruments TGA Q500. The analysis of the data was performed with the Universal Analysis 2000 software. A sample of $10 \mathrm{mg}$ was heated from $25^{\circ} \mathrm{C}$ to $600^{\circ} \mathrm{C}$ at a heating rate of $10^{\circ} \mathrm{C} / \mathrm{min}$ under nitrogen flow.

Differential scanning calorimetry (DSC). DSC was performed with a TA Instruments Q100 DSC. The heating and cooling rates were $10{ }^{\circ} \mathrm{C} / \mathrm{min}$ under a nitrogen atmosphere. For the data analysis, Universal Analysis 2000 software was used.

Matrix-assisted laser desorption/ionization-time-of-flight mass spectrometry (MALDI-ToF-MS). MALDI-ToF-MS measurements were performed with a PerSeptive Biosystems Voyager-DE STR MALDI-ToFMS spectrometer with a $2 \mathrm{~m}$ flight tube in linear mode and a $3 \mathrm{~m}$ flight tube in reflector mode. For the ionization, a $337 \mathrm{~nm}$ nitrogen laser with a $3 \mathrm{~ns}$ pulse was used. The acceleration potential was $20 \mathrm{kV}$ and the data was processed with Voyager software. As matrix 2,4,6trihydroxyacetophenon and as cationization agent diammonium hydrogen 
citrate were used. For the measurement, the sample was dissolved in THF $(5 \mathrm{mg} / \mathrm{mL})$, and the matrix and cationization agent were added (4:1:4 weight ratio). $0.30 \mu \mathrm{L}$ of this solution was spotted on the sample plate and dried at room temperature.

Dynamic mechanical thermal analysis (DMTA). DMTA measurements were performed on a TA Instruments DMA Q800. DMTA samples were cut into rectangular shapes of $10 \mathrm{~mm} \times 5 \mathrm{~mm} \times 0.5 \mathrm{~mm}$. All experiments were performed at a frequency of $1 \mathrm{~Hz}$ and at heating rate of $3{ }^{\circ} \mathrm{C} / \mathrm{min}$. The samples were firmly clamped below $T_{\mathrm{g}}$ and the measurements were performed in a temperature range of -80 to $100{ }^{\circ} \mathrm{C}$. The $T_{\mathrm{g}}$ values determined via DMTA were obtained by taking the maximum value of the $\tan \delta$ peak.

Evaluation of cross-linking and coating performance. The obtained coatings were evaluated using several characterization methods. The solvent resistance of the coatings was assessed through the acetone rub test, in which the sample is rubbed back and forth with a cloth drenched in acetone. If no damage is visible after more than 200 rubs (i.e. 100 'double rubs'), the coating has good acetone resistance. Resistance against rapid deformation was tested using the reverse impact test, performed by dropping a weight of $1 \mathrm{~kg}$ on the back of a coated panel from a height of $90 \mathrm{~cm}$ (ASTM D2794). ${ }^{33}$ The coating hardness was measured using the pencil hardness test, performed by scratching the coating with pencils of increasing hardness using an Elcometer 501 Pencil Hardness Tester. The coating thicknesses were measured through magnetic induction using an Elcometer 224 Digital Surface Profile Gauge.

\section{Acknowledgements}

The work of Liliana Gustini forms part of the research programme of the Dutch Polymer Institute (DPI), project \#796p. This research has also received funding from the European Union's Seventh Framework Program for research, technological development and demonstration under grant agreement no. 289253 (REFINE). Cristina Lavilla is a Marie Curie IEF fellow (FP7-PEOPLE-2013-IEF 625116). Jody Lugger and Bram Teunissen are acknowledged for the support with NMR analysis. Roquette Frères is gratefully acknowledged for supplying sorbitol free of charge.

Keywords: biocatalysis • carbohydrates • polymerization • renewable resources $\cdot$ sustainable chemistry

\section{References}

${ }^{1}$ A. Gandini, Green Chem., 2011, 13, 1061-1083.

${ }^{2}$ T. A. Werpy, J. E. Holladay, J. F. White, Top Value Added Chemicals from Biomass. Volume I: Results of Screening for Potential Candidates from Sugar and Synthesis Gas Pacific Northwest National Laboratory, PNNL-14808 (2004).

${ }^{3}$ A. Houde, A. Kademi, D. Leblanc, Appl. Biochem. Biotech., 2004, 118, 155 170.

${ }^{4}$ M. Rose, R. Palkovist, Chem. Sus. Chem., 2012, 5, 167-176.

${ }^{5}$ Aritomo Yamaguchi , Norihito Hiyoshi , Osamu Sato, Masayuki Shirai, Green Chem., 2011, 13, 873-881.

${ }^{6}$ C. Marquez-Alvarez, E. Sastre, J. Perez-Pariente, Topics in Catalysis, 2004 27, 105-117.
${ }^{7}$ R. Sheldon, Green Chem., 2014, 16, 950-963.

${ }^{8}$ C. Vilela, A. F. Sousa, A. C. Fonseca, A. C. Serra, J. F. J. Coelho, C. S. R. Freire, A. J. D. Silvestre, Polym. Chem., 2014, 5, 3119-3141.

${ }^{9}$ P. F. H. Harmsen, M. M. Hackmann, H. L. Bos, Biofuels, Bioprod. Bioref., 2014, 8, 306-324.

${ }^{10}$ C. Lavilla, A. Alla, A. Martínez de llarduya, E. Benito, M. G. García-Martín, J. A. Galbis, S. Muñoz-Guerra, Biomacromolecules, 2011, 12, 2642-2652.

${ }^{11}$ Y. Yang, W. Lu, J. Cai, Y. Hou, S. Ouyang, W. Xie, R. A. Gross, Macromolecules, 2011, 44, 1977-1985.

${ }^{12}$ Y. Shibata, A. Takasu, J. Polym. Sci. A: Polym. Chem., 2009, 47, 57475759 .

${ }^{13}$ Y. Jiang, A. J. J. Woortman, G. O. R. Alberda van Ekenstein, K. Loos, Polym. Chem., 2015, 6, 5198-5211.

${ }^{14}$ R. C. Pratt, B. G. G. Lohmeijer, D. A. Long, R. M. Waymouth, J. L. Hedrick, J. Am. Chem. Soc., 2006, 128, 4556-4557.

${ }^{15}$ D. Tang, D. Mulder, B. A. J. Noordover, C. E. Koning, Macromol. Rapid Commun., 2011, 32, 1379-1385.

${ }^{16}$ M. Firdaus, M. A. R. Meier, Green Chem., 2013, 15, 370-380.

${ }^{17}$ D. Tang, B. A. J. Noordover, R. Sablong, C. E. Koning, J. Polym. Sci. A Polym. Chem., 2011, 49, 2959-2968.

18 M. K. Kiesewetter, E. J. Shin, J. L. Hedrick, R. M. Waymouth, Macromolecules, 2010, 43, 2093-2107.

${ }^{19}$ A Takasu, Y. Oishi, Y. lio, Y. Inai, T. Hirabayashi, Macromolecules, 2003, 36, $1772-1774$.

${ }^{20}$ R. A. Gross, M. Ganesh, W. Li, Trends Biotechnol., 2010, 28, 435-443.

${ }^{21}$ S. Patai, ed., The Chemistry of Carboxylic Acids and Esters, WileyInterscience Inc., New York, 1969.

${ }^{22}$ L. Gustini, L. Finzel, C. Lavilla, B. A. J. Noordover, M. M. R. M. Hendrix, C Gehrels, C. E. Koning, ACS Sustainable Chem. Eng., 2016, 4, 2259-2268.

${ }^{23}$ J. Uppenberg, M. T. Hansen, S. Patkar, T. A. Jones, Structure, 1994, 2, 293-308.

${ }^{24}$ P. Adlercreutz, Chem. Soc. Rev., 2013, 42, 6406-6436.

${ }^{25}$ M. Garaleh, H. R. Kricheldorf, S. M. Weidner, T. Yashiro, J. Macromol Sci A: Pure Appl. Chem., 2010, 47, 303-308.

${ }^{26}$ S. G. Nanaki, K. Pantopoulos, D. N. Bikiaris, Int. J. Nanomedicine 2011, 6, 2981-2995.

${ }^{27}$ W. N. Sivak, I. F. Pollack, S. Petoud, W. G. Zamboni, J. Y. Zhang, E. J.

Beckman, Acta Biomater., 2008, 4, 1263-1274.

${ }^{28}$ J. Y. Zhanga, E. J. Beckmana, N. P. Piescob, S. Agarwal, Biomaterials 2000, 21, 1247-1258

${ }^{29}$ H. Fu, A. S. Kulshrestha, W. Gao, R. A. Gross, M. Baiardo, M. Scandola, Macromolecules, 2003, 36, 9804-9808.

${ }^{30}$ American Society for Testing and Materials (2010) Standard test methods for hydroxyl groups using acetic anhydride acetylation. ASTM E222-10. ASTM, West Conshohocken.

${ }^{31}$ Z. Zhou, Y. He, X. Qiu, D. Redwine, J. Potter, R. Cong, M. Miller, Macromol. Symp., 2013, 330, 115-122.

${ }^{32}$ P. Dais, A. Spyros, Magn. Reson. Chem., 2007, 45, 367-377.

${ }^{33}$ American Society for Testing and Materials (2010) Standard test method for resistance of organic coatings to the effects of rapid deformation (impact). D2794 - 93 (Reapproved 2010). ASTM, West Conshohocken. 
Entry for the Table of Contents (Please choose one layout)

Layout 2:

\section{FULL PAPER}

((Insert TOC Graphic here; max. w idth: $11.5 \mathrm{~cm}$; max. height: $2.5 \mathrm{~cm}$ ))

Author(s), Corresponding Author(s)*

Page No. - Page No.

Title

Text for Table of Contents: Linear polyesters with pendant hydroxyl groups are synthesized from the sugar alcohol sorbitol in a solvent-free approach, using different (bio)catalysts. From the functional polyesters, bio-based coatings are prepared.

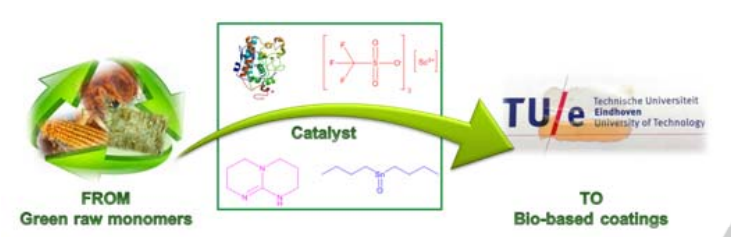

